\title{
Laboreal
}

Volume $16 \mathrm{~N}^{\circ} 1 \mid 2020$

Quando o trabalho real é tabu

\section{O tabu da sedução como trabalho na profissão de ator : elementos de uma investigação de psicodinâmica do trabalho}

El tabú de la seducción como trabajo en la profesión de actuación : elementos de una investigación psicodinámica del trabajo

Le tabou de la séduction comme travail dans le métier de comédien.ne :éléments d'une enquête de psychodynamique du travail

The taboo of seduction as work in the acting profession : elements of an investigation on work psychodynamics

\section{Marie Potiron}

Tradutor. João de Deus Gomes da Silva

\section{(2) OpenEdition}

\section{Journals}

\section{Edição electrónica}

URL: http://journals.openedition.org/laboreal/15948

DOI: $10.4000 /$ laboreal. 15948

ISSN: 1646-5237

Editora

Universidade do Porto

\section{Refêrencia eletrónica}

Marie Potiron, « $\mathrm{O}$ tabu da sedução como trabalho na profissão de ator : elementos de uma investigação de psicodinâmica do trabalho », Laboreal [Online], Volume $16 N^{0} 1 \mid$ 2020, posto online no dia 01 julho 2020, consultado o 08 julho 2020. URL : http://journals.openedition.org/laboreal/15948 ; DOI : https://doi.org/10.4000/laboreal.15948

Este documento foi criado de forma automática no dia 8 julho 2020.

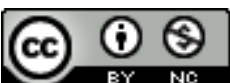

Laboreal está licenciado com uma Licença Creative Commons - Atribuição-NãoComercial 4.0 Internacional. 


\section{O tabu da sedução como trabalho na profissão de ator : elementos de uma investigação de psicodinâmica do trabalho}

El tabú de la seducción como trabajo en la profesión de actuación : elementos de una investigación psicodinámica del trabajo

Le tabou de la séduction comme travail dans le métier de comédien.ne : éléments d'une enquête de psychodynamique du travail

The taboo of seduction as work in the acting profession : elements of an investigation on work psychodynamics

\section{Marie Potiron}

Tradução : João de Deus Gomes da Silva

\section{NOTA DO EDITOR}

Manuscrito recebido em : janeiro 2020

Aceite após peritagem : maio 2020

Tradução : João de Deus Gomes da Silva - joaodedeus@gmail.com

\section{Introdução}

Durante uma enquete em psicodinâmica do trabalho realizada com um pequeno coletivo de atores, reunido por ocasião da preparação de um espetáculo, surgiu o que poderíamos chamar de "tabu" na cooperação vertical: o trabalho de "sedução" instaurado pelos atores em relação ao encenador. 
2 A definição de "tabu", termo e conceito derivado das sociedades polinésias e popularizado por alguns grandes exploradores, refere-se a um sistema de proibições religiosas aplicadas ao que é considerado sagrado ou impuro, no qual silencia-se por medo ou modéstia ; ou ao que é proibido (Le Petit Robert, 2020). 0 uso do termo "tabu" é justificado aqui pelo risco iminente e medo despertado pelos atores de que esse trabalho de sedução seja revelado.

3 Este artigo, um panorama provisório das reflexões ainda em formulação, parte da apresentação e discussão metodológica da enquete para em seguida apresentar os elementos clínicos evidenciados no trabalho de pesquisa - e que foram, portanto, discutidos com os participantes. Por fim, por meio de reflexões mais interpretativas e especulativas, nascidas no rescaldo da investigação, tentarei questionar o significado da instauração desse tabu face às dificuldades e aos sofrimentos específicos no trabalho do ator/atriz descritos nesta investigação.

\section{Investigação : precisão e discussões metodológicas}

4 A investigação em psicodinâmica do trabalho em que este artigo se baseia ocorreu principalmente no ano de 2014. Ela resulta de um trabalho clínico e teórico de vários anos que deu origem inicialmente a uma dissertação de mestrado e depois a uma tese de doutorado dirigida por Christophe Dejours (Potiron, 2017). Partindo de uma clínica do trabalho dos atores/atrizes, complementada por uma perspectiva histórica das evoluções da profissão e das organizações do trabalho teatral, buscou-se promover uma discussão com as abordagens psicanalíticas da arte em torno da questão do trabalho artístico.

5 Esta investigação, vivenciada como um relativo fracasso, nasceu de um pedido particular de um coletivo teatral composto por três atores, constituído em razão de uma encenação teatral. A trajetória da demanda que resultou nesta investigação, faz deste estudo uma exceção na pesquisa clínica. O mundo teatral está longe de ser poupado do sofrimento no trabalho e da psicopatologia do trabalho, como evidenciado pelas histórias relatadas pelos participantes. Mas isso não sai do "meio" profissional ; recorrer à medicina do trabalho ou aos tribunais de justiça do trabalho, é raro.

6 A organização por projetos dificulta a instauração de uma investigação, um dispositivo cujo peso, observado por Dejours, representa uma dificuldade particular no campo do trabalho teatral e mais amplamente da performance ao vivo (Dejours, 1993). Baseia-se em uma economia complexa, na qual algumas companhias bem gratificadas convivem com incontáveis pequenas estruturas, numa busca constante de financiamento e tempo. A montagem de um espetáculo requer pelo menos um mês de ensaio, em um espaço adequado. Não importa onde, o tempo está se esgotando. Planejar uma criação, agendar um cronograma de ensaios, é um quebra-cabeça colossal, especialmente quando há muitos atores. 0 tempo dedicado ao trabalho de criação e ensaio é curto e intenso, os dias de trabalho muito sobrecarregados, os orçamentos apertados. Em seguida, chega a hora da estréia e uma possível turnê - um tempo descontínuo quando os dias de apresentações se seguem - e depois param e depois retomam.

7 A rede, a "família" teatral, é de suma importância. Comediantes e encenadores se encontram frequentemente, mas os coletivos não são os mesmos de um projeto para outro e são efêmeros. Enquanto muitos comediantes mostram, individual ou 
coletivamente, um interesse definitivo em uma abordagem clínica de seu trabalho, empregadores/as - administrativamente falando, as companhias de teatro, na verdade, os encenadores - não vêem interesse em apoiar a instauração de uma investigação para um coletivo que deixará de existir dois meses depois.

8 Há também outras razões : o medo bem fundamentado de desestabilizar a "misteriosa alquimia humana" (Vives, 2008) que preside a criação de um espetáculo, embora, na organização temporal de um coletivo de trabalho teatral, não haja "segunda chance" ; a relutância em revelar a "cozinha" secreta considerada necessária para a "magia" teatral ; que pode, inclusive, se ver a evocar regularmente práticas brutais, mesmo violentas.

9 Esta pesquisa foi somente possível graças ao apoio do encenador, o primeiro portador do pedido, cujo interesse em questões relacionadas ao trabalho é muito presente em suas encenações.

10 A análise da demanda, por ser decorrente de um coletivo efêmero, foi adaptada às especificidades do terreno e sua breve temporalidade, ao mesmo tempo em que esforços foram feitos para respeitar os passos e os princípios fundadores do método de investigação (análise da demanda, reunião de informações, apresentação da investigação e seus riscos, voluntariado dos participantes...) (Dejours, 1993).

11 Este pedido tem uma peculiaridade. Não surgiu, como é o caso da grande maioria das investigações em psicodinâmica do trabalho, da passagem de uma normalidade para a descompensação, de uma crise aguda que sinaliza o fracasso das estratégias de defesa coletiva. Ao contrário, este coletivo de trabalho parece composto de sujeitos em bom estado de saúde, inscritos numa cooperação harmoniosa. 0 sofrimento não aparecendo massivamente sugere, então, que as defesas parecem compensá-lo efetivamente. 0 prazer de trabalhar juntos é evidente. Logo, o pedido está organizado em torno de um desejo comum expresso pelos três atores de tornar visível - em primeiro lugar para si mesmos - o trabalho real, sua complexidade, suas dificuldades e sua relação com a saúde mental. Trata do sofrimento no trabalho, mas de um sofrimento normal, entendido no sentido de "normalidade do sofrimento" (Dejours \& Molinier, 1994).

Tal pedido apresenta dificuldades particulares e consideráveis, que não foram plenamente consideradas logo no início - e a análise desta demanda, pouco habitual, revelou-se insuficiente. É impossível elaborar aqui em detalhes todas essas dificuldades [1], mas podemos referir que algumas estão relacionadas com estratégias coletivas de defesa contra o sofrimento. Na medida em que estas estratégias não falharam, a questão de sua visibilidade surge em primeiro lugar. Para os clínicos e pesquisadores envolvidos nesta investigação, a questão se apresentou sobre o ângulo da possibilidade de desestabilização pelo processo de investigação e do risco para a saúde que tal desestabilização poderia provocar. A postura clínica foi, portanto, cautelosa em relação às estratégias defensivas sobre as quais poderíamos ter "caído".

13 Na minha opinião, o relativo fracasso desta pesquisa, expressa pelos participantes na forma de decepção ("não aprendemos muita novidade sobre o nosso trabalho") é o resultado dessa posição cautelosa. Num balanço posterior, parece-me que essa opção clínica pode ser analisada como resultado de um trabalho de demanda insuficiente, tendo faltado a potência do pedido de análise. Também é possível considerar que se estaria lidando com uma inversão da demanda, nesse caso, que a demanda teria partido do pesquisador, uma armadilha comum para um campo de tese. No entanto, o interesse dos pesquisadores não é - se integrado numa abordagem elaborada - um obstáculo à 
escuta clínica, mas configura-se como um motor. Assim sendo, esta última interpretação não explica a participação assídua dos participantes na pesquisa, nem seu comprometimento, nem sua decepção. O erro clínico foi, a meu ver, não ter considerado que o pedido endereçado aos clínicos implicaria necessariamente questionar as defesas. Precisamos acrescentar que uma apresentação rigorosa da disciplina, seu método, seus riscos (Dejours, 1993), foi feita para os participantes, abordando, portanto, a análise das defesas. Entretanto, tais defesas talvez não fossem tão operantes quanto acreditávamos. Do meu ponto de vista, a decepção expressa pelos participantes ao final da pesquisa pode, logo, ser explicada por essa falta de audácia na investigação das defesas.

14 A pesquisa foi realizada em conjunto por dois clínicos, pesquisadores, sob a supervisão de Christophe Dejours. Um dia de "observação" foi seguido por quatro reuniões de cerca de duas horas, com cerca de dez dias de intervalo e duas sessões de restituição do relatório, o que constitui uma adaptação metodológica significativa, vinculada às necessidades do campo. De fato, a sessão marcada para discussão do relatório havia sido marcada na manhã de uma das primeiras apresentações do espetáculo (a terceira). A pedido dos atores e por razões práticas, ela foi deslocada por algumas horas e, portanto, teve que terminar cerca de duas horas antes da apresentação. $O$ final da sessão foi, assim, invadido pelos afetos de uma estreia iminente e pelo "nervosismo" dos atores, dificultando - para dizer o mínimo - continuar a discussão sobre a relação e o compartilhamento com o encenador (veremos mais tarde como esse episódio pode ser entendido). Considerando a impossibilidade de continuar a discussão e o seu caráter inacabado, decidimos, assim, coletivamente, adiar o fim desta discussão. Uma segunda sessão de discussão do relatório e a possibilidade de compartilhá-lo com o encenador ocorreu vários meses depois, durante uma pausa na turnê teatral. Essa segunda discussão resultou na decisão coletiva por parte dos atores de compartilhar o relatório com o encenador, o que ocorreu semanas depois.

A enquete ocorreu principalmente durante o período de ensaio, que, naturalmente, teve um grande efeito sobre os elementos clínicos. A situação de ensaio difere do espetáculo, por um lado, pela natureza do trabalho, orientada para uma atividade de pesquisa de movimentos, emoções, caracterização dos personagens, etc. ; por outro, constituindo um "frente à frente" entre o encenador e os atores. A situação de representação corresponde ao encontro com um público e ao apagamento da presença real do encenador. O relatório inicialmente elaborado pelos clínicos, depois discutido e alterado pelos participantes da pesquisa, foi cauteloso, assim como nosso posicionamento clínico nesta pesquisa.

\section{Elementos clínicos}

\subsection{O lugar essencial do encenador na organização do trabalho}

O trabalho dos atores/atrizes participantes da pesquisa ocorre em uma complexa organização de trabalho, articulando diferentes níveis - a organização geral do setor de entretenimento ao vivo, o regime de intermitência [2], a companhia teatral. Dentro dela, a lacuna entre a organização prescrita e a organização real do trabalho é desempenhada, em particular, em torno do lugar do encenador. Na organização oficial, prescrita, o encenador é como os atores, o gerente de produção, o administrador, 
funcionário da empresa e não há hierarquia formal entre eles. Na organização real, o encenador dirige a companhia.

Sob o plano da divisão técnica do trabalho, o encenador distribui os papéis aos atores que escolhe durante um processo complexo, no qual a audição ocupa um lugar essencial. Seu trabalho de direção é baseado em uma leitura singular da peça. Ele define datas e horários de ensaio - levando em conta compromissos profissionais e necessidades pessoais uns dos outros. Ele orienta a atuação, decide sobre os movimentos, a ocupação do espaço do palco, os figurinos, a cenografia, cooperando com as chamadas equipes "técnicas" e "artísticas" [3]. Ele é, portanto, muito claramente "o chefe", como os atores o chamam, apesar da discordância que essa marca hierárquica desperta nele. Dirigir atores também pode ser entendido como uma variação teatral de "organizar a obra". Esse tipo de organização de trabalho é bastante específico ao teatro público, subvencionado.

\subsection{Ensaios e performances}

18 Na situação dos ensaios, os atores se encontram, em relação aos seus colegas, bem como ao encenador, em uma posição de reciprocidade : cada um vê os outros trabalhando isto é, tentando, se confrontando com a realidade, suportando o fracasso, enganando e recomeçando.

19 O encenador, no entanto, tem um lugar específico. Ele é o único que está no lugar do público para todas as cenas. Deste lugar - o único possível para sua tarefa - ele ordena e estrutura o que o público verá. Parte do trabalho que os atores fazem com ele é um "treinamento", uma repetição, um mínimo, não só do desdobramento do espetáculo, mas também do calvário da cena - situação que veremos mais adiante que contém um grande risco que gera um sofrimento particular.

\subsection{Trabalho prescrito, trabalho real}

Em qualquer situação de trabalho, existe uma lacuna entre o trabalho prescrito e o trabalho real. Na situação de trabalho em que esta investigação se baseia, o estatuto da prescrição é "ser" e não "fazer". O trabalho "sincero" está localizado no lado do "ser" enquanto o "fazer" refere-se a uma certa falsidade, a uma fabricação superficial ("faça o ator"). 0 que é dito no registro de "ser" corresponde, no entanto, a um trabalho, a um "trabalhar", envolvendo um saber-fazer profissional, regras técnicas, linguageiras, sociais, éticas, produtos da atividade deôntica.

O trabalho real, efetivo, referido nesta pesquisa pode ser dividido em trabalho de encenação, jogo, palco, e trabalho de busca de emprego, ou casting, trabalho de gestão do "status" de intermitente do espetáculo, trabalho de "cultura de rede" (tomo expressões usadas pelos participantes na pesquisa), que prontamente entrelaça registros pessoais e profissionais e se organiza em termos de uma "família" de trabalho, etc.

O trabalho de "encenação" é descrito de início como uma obra de abertura de si e de pesquisa por "geografias", de estados emocionais, imaginários, em que às vezes ocorre um "achado", que responde a um pedido, uma prescrição do encenador, mas também a excede. O achado contém uma dimensão de surpresa, do inesperado que o torna 
precioso e difícil de alcançar. Esse trabalho de pesquisa às vezes falha: eles "não conseguem", não encontram o que o encenador pede.

Neste momento, de pesquisa específica para a fase dos ensaios, como na representação, o trabalho imaginário também é igualmente e no mesmo movimento, eminentemente corporal. o corpo é, de fato, o lugar, o material e o instrumento de trabalho - individual, mas também coletivo - e as regras da profissão lhe dão um lugar essencial.

\subsection{Cooperação entre encenador e atores}

24 A cooperação - vertical e horizontal - é essencial para o trabalho de jogo.

250 trabalho de pesquisa dos atores/atrizes está profundamente inscrito na cooperação vertical - entre ator/atriz e encenador/encenadora. Uma parte importante do trabalho real dos atores é adivinhar, decifrar o que o encenador quer e busca - inclusive implicitamente, escondido, inconsciente - e responder a essas demandas às vezes não comentadas, divergentes ou até mesmo contraditórias, baseadas em indicações de clareza às vezes relativa (ilustrada : "o texto rasteja no chão e sobe sua perna").

\subsubsection{Autoridade}

Na situação de trabalho que nos interessa aqui, a autoridade é conferida ao encenador, não apenas pelo seu status, na organização do trabalho, como gestor da companhia e na encenação, mas também pelo reconhecimento, por parte dos atores, de sua habilidade, suas competências como profissional e sua capacidade de se afastar de seu lugar de autoridade, em benefício do trabalho conjunto, quando um dos atores faz uma interessante proposta de encenação.

27 A concessão de autoridade, portanto, está no controle daqueles sobre os quais ela é exercida e não pode ser imposta apenas pela organização do trabalho. 0 desdém ou a negação dessa característica inevitavelmente levariam a "greve do zelo" e fracasso (Dejours, 2009) - o que os participantes da pesquisa descrevem sobre experiências anteriores.

28 À esta autoridade responde, antes de tudo, uma forma de obediência nos atores, que nem todos os participantes da pesquisa assumem da mesma maneira, mas todos insistem em sua necessidade. Diferente de uma obediência cega. É um trabalho racional, baseado no reconhecimento da qualidade do trabalho do encenador - um julgamento de beleza em suas encenações anteriores - e na confiança. Uma vez concedida a confiança, a decisão de cooperar foi tomada, os atores se entregam, por um tempo, de corpo e alma para o encenador. É um modo de obediência que decorre não só do equilíbrio de poder, mas das necessidades do trabalho.

29 Este primeiro tempo de obediência é seguido por outro, igualmente essencial, discutido desde a nossa primeira sessão de trabalho : o da "emancipação", que vem no final do processo criativo e que um dos participantes do coletivo da pesquisa descreve da seguinte forma : "Em algum momento, depois de fazeres tudo o que ele pediu para você fazer, você entendeu. Agora é comigo ».

30 Trata-se de um momento problemático, que pode colocar a cooperação vertical e a autoridade em crise na medida em que implica, por parte do encenador, permitir que esse processo de emancipação ocorra, que é necessariamente acompanhado de "deslizes" no espetáculo, dos quais ele não está à origem, um momento em que sua 
presença se tornou quase inútil. A cooperação é, portanto, marcada por um processo de empoderamento e emancipação gradual dos atores em relação ao encenador, pautado por uma reorganização da cooperação coletiva, horizontal e vertical. Durante este, o lugar do encenador é alterado pela ação coletiva. A cooperação horizontal dá o passo na cooperação vertical, o encenador é distanciado pelo coletivo de trabalho - espetáculo em uma lógica que adere o mais próximo possível às necessidades da cena e da representação.

31 Assim, a obediência e a autoridade são um passo necessário no caminho para sua dissolução, quando se tornarem inúteis.

\subsection{2. "Desejo" e "amor"}

32 A escolha dos atores pelo encenador aparece repetidamente, nesta investigação como em outros momentos clínicos, como resultado de um "desejo". O significado desse movimento desejado parece essencial. É o encenador que "deseja" o ator, não o contrário - "o desejo só pode vir dele". Falhas dolorosas na cooperação vertical encontram uma explicação em uma inversão desse movimento de desejo - a manifestação, pelos atores, do desejo de trabalhar com um encenador.

Os atores também evocam repetidamente a relação entre encenador e ator em termos de amor. "Quero que ele me ame", diz um participante sobre sua relação com encenadores em geral.

o que é enigmático nos termos "amor" ou "desejo" parece estruturar a cooperação vertical.

Na psicodinâmica do trabalho, a presença de amor e sexualidade no trabalho é pensada em termos de confusão e considerada um risco, um desvio, que ocorre às custas do trabalho. A dinâmica do reconhecimento, é mediada por julgamentos de beleza e utilidade, trata-se do trabalho e não da pessoa (Dejours e Gernet, 2009). Somente em um segundo momento, os benefícios do reconhecimento podem ser repatriados para o registro de identidade e amor próprio (Potiron, 2015). A confusão entre reconhecimento e amor, entre pedido de reconhecimento e pedido de amor, geralmente sinaliza uma ruptura da dinâmica de reconhecimento e suas condições de existência - confiança, visibilidade do trabalho, espaços de deliberação, etc.

36 Na erotização defensiva das relações de dominação (Demaegdt, 2008), a erotização está a serviço das defesas, sempre ambíguas em relação à saúde, pois, ao não nos permitir pensar sobre o que causa o sofrimento, protegem os riscos de descompensação ; mas ao mesmo tempo contribuem para estreitar o pensamento e congelar a situação que causa sofrimento.

Dejours evoca o risco de confusão entre autoridade e amor, em sua exploração da "dinâmica" da autoridade (Dejours, 2009). Aqui, há claramente uma ambiguidade na autoridade, um "deslize" em direção ao registro do amor, que tanto os participantes da pesquisa quanto o encenador parecem cientes, mas que não é acompanhado (pelo menos para os atores) por uma negação das relações de dominação, parecendo excluir o papel defensivo do fenômeno.

38 A pesquisa constatou "falhas" na dinâmica do reconhecimento. Um dos atores se sentiu mais reconhecido por seu papel como um "pivô" da cooperação do que por sua representação. Recebe mais julgamentos de utilidade do que de beleza, o que constitui uma falta de reconhecimento. O papel de um outro é significativamente reduzido 
durante cortes de texto projetados para adaptar a duração do espetáculo para o festival de Avignon. O papel, seu escopo dramático, cênico e textual significa muito para a dinâmica do reconhecimento. Estes cortes de textos foram, portanto, um momento de crise para este ator. Estas questões foram discutidas e as condições para a possibilidade da dinâmica de reconhecimento parecem permanecer presentes durante a duração da investigação.

Pelo que pudemos constatar, o aparecimento do registro de amor e desejo, neste coletivo, não parece ser o resultado de uma erotização defensiva das relações de dominação, nem de um desvio da dinâmica do reconhecimento. Para os participantes da pesquisa, o trabalho teatral, concebido e praticado neste coletivo, parece envolver o jogo com a ambiguidade entre autoridade e amor, colocado aqui a serviço do trabalho, individual e coletivamente. Essa mudança parece mais amplamente fazer parte de uma certa cultura de trabalho, reivindicada por Antoine Vitez, quando afirma como regra de direção do trabalho : "Temos que (...) amar nossos atores" (Vitez, 1984)

Essa confusão, esse desvio entre trabalho e amor, parece estar ligada à organização do trabalho teatral e suas evoluções.

41 "Encenação" e "encenador" são "invenções" relativamente recentes (Folco, 2013) na longa história do teatro ocidental e suas organizações do trabalho. O que hoje é integrado na "encenação" e no trabalho do encenador era antes (até a virada do século XIX e XX) assegurado por (ou distribuído entre) o autor, um ator, um decorador, o encenador do teatro...

42 Na atual era do "reinado" dos encenadores, (logo infelizmente derrubados, se não já, por gestores culturais (Proust, 2003, Chiapello, 1998) o encenador é um "criador-chefe" que propõe uma leitura, uma visão, uma escrita teatral, uma obra singular. Se quiserem participar, os atores devem chegar o mais perto possível da "visão" do encenador. Isso implica uma "auto-entrega" (Sorignet, 2010) de corpo e alma ao encenador durante o tempo da criação, atitude impossível sem uma grande confiança. O equilíbrio é provavelmente precário. Se a ambiguidade for longe demais, há o risco de perder a dimensão do trabalho.

43 No entanto, as experiências dolorosas dos atores nesse sentido não são muito associadas a uma mudança para o registro do amor, o que faria com que a dimensão do trabalho fosse perdida [4]. Tais experiências são, para alguns, a radicalização de uma autoridade transformada em autoritarismo, quebrando a confiança dos atores em relação ao encenador ; tornando impossível a "autoentrega" (Sorignet, 2010) necessária para o trabalho de pesquisa de palco e provocando o recuo sob um tecnicismo desalmado cheio de tédio. Para outros, estas experiências correspondem ao desaparecimento do "desejo" do encenador, que parece ser um risco significativo para a saúde mental.

\subsubsection{Um trabalho de sedução?}

O trabalho de sedução foi particularmente debatido durante o encontro previsto para a discussão do relatório, quando a possibilidade de compartilhamento deste relatório de pesquisa com o encenador foi avaliada. Como já foi referido, esta sessão foi problemática, pois, invadida pelos efeitos psíquicos sobre os atores da iminente apresentação, no terceiro dia do espetáculo, resultou numa discussão inacabada e uma decisão temporária de não compartilhar o relatório com o encenador por causa da 
relutância de um dos participantes. Um segundo encontro foi previsto para continuar a discussão três meses depois, quando definitivamente o coletivo deliberou pelo compartilhamento do relatório. $O$ que teria se passado entre estes dois momentos que culminou com tal decisão? "Bom, nós estreamos!», respondem os participantes da enquete. Na realidade, as semanas e meses de turnê permitiram consolidar a cooperação horizontal durante os ensaios e a cooperação vertical durante os espetáculos.

Para aquele, entre os três participantes, que não desejava compartilhar o relatório, a revelação da "cozinha" interna do ator pode levar ao desaparecimento do desejo do encenador. Ele teme as possíveis consequências sobre o trabalho em andamento, começo da turnê, e na cooperação a longo prazo. Ele formula seu medo de "matar a magia, matar o desejo" do encenador ao revelar o trabalho "de sedução" - revelação do desejo do encenador como resultado do trabalho do ator, revelação da "magia" como um trabalho. "Um encenador, você tem que fazê-lo sonhar, ele tem que ser capaz de sonhar com você. Se você explicar a ele como você o faz sonhar, inevitavelmente não funciona mais!»

Os outros dois participantes da pesquisa, que trabalham com o encenador há muito tempo, não partilham esse medo de compartilhar o relatório da enquete com o encenador, embora concordem com essa análise, em um nível mais global : "Você pode, em uma frase, tirar o desejo do encenador".

Uma parte importante do trabalho real e invisível de um ator é então revelado : levar em conta esse "desejo" cujas nascentes e natureza precisam permanecer enigmáticas para aqueles que o despertam: "fazer o encenador sonhar" ou "deixá-lo sonhar"; despertar, nutrir suas reflexões teatrais, apoiando o ator, através da peça, das proposições da peça, baseadas em indicações, que como vimos, poderiam ser divergentes, implícitas, abstratas, exigindo um trabalho arriscado de "tradução". Considerar esse fenômeno como um trabalho justifica-se na medida em que esse "trabalho de sedução" envolve um conjunto de "atividades instauradas [pelos atores] para lidar com o que não é dado pela organização prescrita do trabalho" - ou seja, pelas indicações do encenador (Davezies, 1993). Para os atores, trata-se de "mobilizar seu corpo, sua inteligência, sua pessoa, por uma produção de valor de uso" (Dejours, 1998)

Esse trabalho de sedução do encenador começa na fase da audição, quando o encenador escolhe os atores para cada um dos papéis da peça. Ele é voltado para a escolha pessoal do encenador de "boas pessoas" com qualidades particulares.

\section{0 sentido do "tabou" para o trabalho}

o "tabu" não é sobre a sedução em si, mas sobre o fato de ser em si um trabalho. Só é ativo no que diz respeito ao encenador, na cooperação vertical e não na cooperação horizontal. $O$ que permite a implementação desse tabu à luz das diferentes características e dificuldades do trabalho dos atores?

\subsection{O desaparecimento do desejo : um risco maior suspendendo o medo}

50 "O medo no trabalho é um perigo psíquico muito comum. Medo de acidente, ferimentos, paralisia ou morte para trabalhadores da construção civil, mecânicos, 
metalúrgicos e caminhoneiros, transportadores, policiais, marinheiros; medo de sangue, contaminação, contato com o cadáver ou erro profissional entre médicos, cirurgiões." (Molinier, 2006).

Entre os atores participantes da pesquisa e em muitos outros que encontramos no curso desta pesquisa clínica, o desaparecimento do desejo do encenador se apresenta como o risco maior no trabalho, causando medo. As histórias quase épicas de tais episódios do desaparecimento do desejo do encenador, mostram consequências devastadoras para a cooperação vertical, mas também horizontal e para a saúde mental dos protagonistas.

\subsection{Instauração do "tabu" e do lugar do encenador}

A invisibilização do trabalho de sedução pode talvez ajudar a solidificar o lugar do encenador. Os atores permanecem, assim, criaturas, e os encenadores, criadores, o que preserva a dinâmica do "desejo", que acabamos de ver como parecendo essencial para o trabalho coletivo e para a preservação da saúde mental dos atores.

dém disso, na organização do trabalho teatral aqui referida, o encenador ocupa um espaço central e organizador, não só na administração das estruturas em que os espetáculos são construídos - as companhias, mas também no trabalho dos ensaios. Se a organização do trabalho teatral centrado no encenador tem certas desvantagens, que os participantes da pesquisa discutem, o encenador quando ele é reconhecido como "bom" ou "forte" - o que parece ser o caso aqui - constitui um recurso poderoso para a obra - arte - do jogo e seu desenvolvimento, promessas de subversão do sofrimento no prazer e poderosas recompensas para a sublimação.

A "invenção" da encenação representou, assim, na história teatral, a abertura de novos horizontes. Vilar, embora tão crítico do termo e da função de "encenador" aponta que "os verdadeiros criadores dos últimos trinta anos não são os autores, mas os encenadores".

\subsection{No que diz respeito à situação de representação}

O encenador é o primeiro público para os atores. A instauração de um "tabu" do trabalho de sedução a ele endereçado prepara a experiência da representação como uma "máquina para fazer o público sonhar", mas que contém um risco significativo. Essa dimensão do trabalho emergiu durante o último encontro, numa controvérsia entre os participantes sobre o eventual compartilhamento do relatório com o encenador e sob a pressão em razão da proximidade da entrada em cena, geradora de tensão e fragilidade. A questão do quadro clínico desempenha um papel essencial aqui. Esta penúltima sessão de trabalho foi reagendada após um pedido dos atores por, nos dizem eles, razões práticas de deslocamentos.

Nenhum dos atores, dada a sua experiência no palco, e ao contrário de nós, clínicos, pesquisadores, não poderia ignorar a inadequação da proposta de realizar tal discussão nos minutos que antecedem o espetáculo. Pode-se, portanto, questionar o significado de tal conduta. Parece-me que poderia ser entendida como uma convocação feita pelos atores - a nós clínicos, pesquisadores - a fim de nos mostrar os efeitos daquilo que, por definição, não se pode dizer nem se ouvir : o sofrimento específico a que este trabalho expõe. Trata-se do medo da cena - banalmente chamado de "trac", en francês, que não faz justiça à violência de suas manifestações. Medo do fracasso em cena, que consistiria 
em não mais conseguir conduzir, seduzir, "fazer o público sonhar" e poderia se traduzir pela sensação devastadora de vazio e ridicularização [5].

\section{À guisa de conclusão}

57 Esta pesquisa nos permite ver como, dentro de um coletivo teatral, as relações de dominação constitutivas da organização do trabalho podem ser subvertidas por/e em cooperação. 0 surgimento do "amor" participa dessa subversão. Esse "amor", nascido das especificidades do trabalho e a seu serviço, não deve ser confundido com uma erotização defensiva, estreitando o pensamento e congelando a situação que faz sofrer. Também não deve ser confundida com abuso e violência, especialmente violência sexual, que, nos mundos da arte e do entretenimento, quase sempre se esconde atrás das exigências de "arte" e "talento" - duas noções que a clínica do trabalho artístico permite questionar de forma frutífera.

[1] Para uma análise detalhada destes aspectos, ver o capítulo 2 da tese (Potiron, 2017).

[2] Os profissionais do ramo de "entretenimento" - "técnicos" e "artistas" - são cobertos na França por um regime específico de seguro-desemprego, permitindo-lhes, quando atingiram um número especificado de horas (atualmente 507) em um período fixo (atualmente 10 meses) - para os empregados dos setores de entretenimento ao vivo, cinema ou audiovisual - receberem um subsídio de desemprego calculado de acordo com as remunerações cobradas.

[3] Para uma discussão sociológica dessa categorização de tarefas em performance ao vivo, ver Bense Ferreira Alves (2007).

[4] Um coletivo misto ou feminino teria tido, sem dúvida, outras narrativas. As violências sexistas e sexuais muito comuns no entretenimento ao vivo são pouco denunciadas juridicamente por causa de um acobertamento poderoso.

[5] Ver nesse sentido a discussão que permite uma clínica do trabalho de atuação no texto de Von Kleist sobre o teatro de fantoches (Von Kleist, 1810) e a análise proposta por J.M. Vives (Vives, 2008) (cfr Potiron, 2017).

\section{BIBLIOGRAFIA}

Bense Ferreira Alves, C. (2007). Le théâtre, l'intermittent et le permanent. Coopérer pour se stabiliser dans l'emploi. Sociétés contemporaines, 66(2), 17-36. https://doi.org/10.3917/soco. 066.0017

Chiapello, E. (1998). Artistes vs managers. Paris : Métailié. https://doi.org/10.3917/meta.chiap. 1998.01

Davezies, P. (1993). Éléments de psychodynamique du travail. Éducation permanente, 116, 33-46.

Dejours, C. (1993). Travail, usure mentale. Paris : Bayard.

Dejours, C. (1998). Travailler n'est pas déroger. Travailler, 1, 5-12.

Dejours, C. (2009). Travail vivant. Travail et émancipation (Tome 2). Paris : Payot. 
Dejours C., \& Gernet, I. (2009). Évaluation du travail et reconnaissance. Nouvelle revue de psychosociologie, 8 (2), 27-36, https://doi.org/10.3917/nrp.008.0027

Dejours, C., \& Molinier, P. (1994). De la peine au travail. Autrement, 142, 138-151.

Demaegdt, C. (2008). Méfiance, violence et sexualisation secondaire dans le métier de surveillance. Travailler, 20(2), 77-97, https://doi.org/10.3917/trav.020.0077

Folco, A. (2013). La querelle sur les origines de la mise en scène moderne et les enjeux mémoriels autour de la figure d'Antoine. Revue d'Historiographie du Théâtre, 1, https://sht.asso.fr/revue/ lecriture-de-lhistoire-du-theatre-et-ses-enjeux-memoriels-2/

Molinier, P. (2006). Les enjeux psychiques du travail. Paris : Payot \& Rivages.

Le Robert (2020). Tabou. Dans Le Petit Robert de la langue française.

Potiron, M. (2015). Psychodynamique de la reconnaissance et identité. Le Carnet Psy, 193(8), 27-33, https://doi.org/10.3917/lcp.193.0027

Potiron, M. (2017). Psychodynamique du plaisir et de la souffrance au travail dans le métier de comédiens : clinique d'un travail artistique et psychanalyse (Thèse de doctorat). Université Paris Descartes, Paris, France.

Proust, S. (2003). La communauté théâtrale. Entreprises théâtrales et idéal de la troupe. Revue française de sociologie, 44(1), 93-113, https://doi.org/10.3917/rfs.441.0093

Sorignet, P.E. (2010). Danser : Enquête dans les coulisses d'une vocation. Paris : La Découverte.

Vitez, A. (1984/1991). Aimer nos acteurs, Journal de Chaillot, 1. In D. Sallenave \& G. Banu (coord.), Antoine Vitez, Le théâtre des idées (pp. 121-122). Paris : Le messager- Gallimard.

Vives, J.M. (2008). Un exemple de cognition corporelle et de son utilisation : le travail de l'acteur. Cahiers de psychologie clinique, 1(30), 75-89, https://doi.org/10.3917/cpc.030.0075

Von Kleist, H. (1810/2004). Sur le théâtre des marionnettes (trad. J.C. Schneider). Paris : Séquences.

\section{RESUMOS}

Este artigo reflete sobre o "tabu" do "trabalho de sedução", durante uma investigação em psicodinâmica do trabalho com um grupo de atores. Mostra que uma parte importante do trabalho real do ator/atriz consiste em "seduzir" o encenador, depois o público. No final da investigação, parte do coletivo de atores recusa-se temporariamente a compartilhar o relacionamento ocorrido com o encenador por medo de "matar a magia, matar o desejo", ao desvendar esse "trabalho de sedução". Após uma primeira sequência de apresentação e discussão metodológica, que permitirá colocar em perspectiva os elementos clínicos resultantes da pesquisa, expõe-se os mesmos e seus vínculos com a organização do trabalho. Interrogamo-nos, em seguida, sobre o significado da instauração desse "tabu" no que diz respeito às dificuldades do trabalho de um ator/atriz, como nesta pesquisa, e à luta contra os sofrimentos específicos aos quais estão expostos estes trabalhadores no exercício do trabalho de sedução.

Este artículo propone una reflexión sobre el "tabú" del "trabajo de seducción", durante una investigación de psicodinámica de trabajo realizado con un grupo de actores. Reveló que una parte importante del trabajo real del actor/ actriz es "seducir" al director, luego al público. Al final de la investigación, parte del colectivo de actores se niega temporalmente a compartir el relato con el director por temor a "matar la magia, matar el deseo", al revelar este "trabajo de seducción ". Despuès de una primera secuencia de presentación y discusión metodológica que 
permitirá poner en perspectiva los elementos clínicos, exponerlos sus vínculos con la organización del trabajo. Luego preguntamos sobre el significado de la establecimiento de este "tabú" con respecto a las dificultades específicas del trabajo de un/a actor/triz, tal que aparece en esta investigación, y a la lucha contra los sufrimientos específicos a los que expone a quienes 'ejercicio.

Clique ou toque aqui para introduzir texto.Une réflexion sur le "tabou» du "travail de séduction", lors d'une enquête de psychodynamique du travail, menée avec un collectif de comédiens, révèle qu'une part importante du travail réel consiste à “séduire » le metteur en scène, puis le public. En fin de l'enquête, une partie du collectif refuse temporairement de partager le rapport avec le metteur en scène craignant de " tuer la magie, tuer le désir ». Il s'agira donc, après une première séquence de présentation et de discussion méthodologique qui permettra de mettre en perspective les éléments cliniques de l'enquête, d'exposer ces derniers et leurs liens avec l'organisation du travail. Nous nous interrogerons ensuite sur le sens de la mise en œuvre de ce "tabou" au regard des difficultés propres au travail de comédien.ne tel qu'il apparaît dans cette enquête et de la lutte contre les souffrances spécifiques auxquelles il expose ceux qui l'exerce.

This paper offers a reflection about the "taboo" of "seduction work", which appeared during a work investigation on psychodynamic with a group of actors. This has indeed revealed that an important part of an actor/actress real work consists in "seducing" the director, then the audience. At the end of the investigation, part of the collective of actors temporarily refuses to share the resulting report with the director. The argument was the fear of "killing the magic, killing desire" by disclosing this "work of seduction". Therefore, after a first moment of presentation and methodological discussion, which will put into perspective the clinical elements emerging from the investigation, such elements, and their links with the organization of work, will be exposed. We will then question the meaning of this "taboo" related to the specific difficulties of an actor/actress's work as it appears in this investigation and to the sufferings they face when performing the seduction work.

\section{ÍNDICE}

Palabras claves: actor, trabajo, sufrimiento, seducción, teatro

Keywords: actor/actress, work, suffering, seduction, theater

Palavras-chave: ator/triz, trabalho, sofrimento, sedução, teatro

Mots-clés: comédien.ne, travail, souffrance, séduction, théâtre

\section{AUTORES}

\section{MARIE POTIRON}

Institut de Psychodynamique du Travail (IPDT), 7 rue Clovis, 75005 Paris

mariepotiron@yahoo.fr 